Journal of Diagnostic Pathology 2011 (6); 1: 17-27

\title{
Changing trend of oesophageal adenocarcinoma and cardia carcinoma incidence; review of literature and analysis
}

Wijetunge $S^{1}$, Suraj $\mathrm{P}^{2}$

\section{Abstract}

Objective: To assess the incidence trends of oesophageal adenocarcinoma and cardia carcinoma in Asian countries based on published literature.

Method: Medical literature was searched by using MEDLINE (1991 to 2011). Latest incidence data were obtained from the web site of the International Agency for Research on Cancer.

Results: In the Asian countries squamous cell carcinoma (SCC) remains the most common oesophageal carcinoma. In the East Asian region, although the incidence of oesophgeal adenoacarcinoma (OAC) is relatively high, each country appears to have different incidence trends of OAC. In most of these countries relative incidence trends of cardia carcinoma (CC) appear to follow those of OAC, regardless of the direction of the trend. CC and gastric non cardia carcinoma (GNCC) have opposing trends.

Conclusion: These observations support the hypothesis that aetiopathogenesis of CC and GNCC are different. In South Asian countries, published data are not adequate to comment on the incidence trends of OAC and CC.

Key words: Oesophagus, carcinoma, adenocarcinoma, cardia, gastro-oesophageal junction, incidence, trends, Asia

\section{Introduction}

Squamous cell carcinoma (SCC) has been the most common tumour in the oesophagus with adenocarcinoma coming second, a long way behind the former. However, a steady rise in the incidence of oesophageal adenocarcinoma (OAC), with declining incidence of SCC, has been reported in North America and Western Europe, since the 1970s. Presently, OAC has taken over SCC to become the most common oesophageal cancer, in North America and in some countries of Western Europe $(1,2,3,4)$. In the USA the relative incidence of OAC has risen from $23.9 \%$ to $161 \%$ during 1976 - 2007 (SEER Cancer statistics).

The aetiopathogenesis of oesophageal SCC (OSSC) and OAC are different. The

${ }^{1}$ Department of Pathology, Faculty of Medicine, University of Peradeniya, Sri Lanka.

${ }^{2}$ National Cancer Control Programme, Sri Lanka.

Correspondence: Wijetunge S, Department of Pathology, Faculty of Medicine, University of Peradeniya, Sri Lanka.e-mail: suwijetunge@gmail.com 
Changing trend of oesophageal adenocarcinoma and cardia carcinoma incidence; review of literature and analysis

aetiology of OSCC is uncertain and factors such as, tobacco smoking, consumption of alcohol and hot beverages have been implicated $(5,6,7)$. However the aetiopathogenesis of OAC is well established and is as follows; gastro-oesophageal reflux induced damage in the oesophageal squamous epithelium leading to cardiac metaplasia of the oesophagus leading to intestinal metaplasia of cardiac mucosa of the esophagus (Barrett oesophagus) leading to increasing dysplasia leading to adenocarcinoma $(8,9,10,11,12)$. Barrett oesophagus significantly increases the risk of OAC development $(8,11,12)$.Therefore, it is important to recognize the rising trend of OAC to strengthen surveillance for Barrett oesophagus in patients with gastro-oesophageal reflux disease (GORD). The prevalence of GORD is higher in the West $(10-20 \%)$ compared to Asia (<5\%) (13).

The rising incidence of cardia carcinoma (CC) similar to OAC has been observed in North America and Western Europe $(4,14,15)$. In the USA, OAC and CC are the most rapidly increasing malignancies (14). However the incidence of gastric non cardia carcinoma (GNCC) shows a decreasing trend in these countries. Clinically and aetiologically too CC and gastro-oesophageal junctional carcinoma have been shown to have similarities to OAC as opposed to GNCC $(15,17,18,19,20,21,22)$.

\section{Objective}

To analyse the incidence trend of OAC and CC in Asia based on published data.

\section{Materials and Methods}

A MEDLINE search was done for period 1991 to 2011. The latest incidence data were obtained from the web site of the International Agency for Research on Cancer (IARC) (3). Selection of countries for the review was based on the availability of relevant data over a sufficiently long period of time to discern incidence trends. In the absence of published data, incidence trend in Sri Lanka was analysed using data from the National Cancer Control Programme. West Asia was excluded due to marked differences in socioeconomic and ethnic profiles. The indicators used to demonstrate the trends were, relative incidence of OAC and relative incidence of $\mathrm{CC}$. These indicators were calculated by using data from reviewed articles. The relative incidence of OAC was calculated by dividing the incidence of OAC by the incidence of OSCC. The relative incidence of $\mathrm{CC}$ was calculated by dividing incidence of CC by incidence of GNCC. Both indicators were given as percentages (ie. multiplied by one hundred).

\section{Results}

In Asia, SCC remains the most common oesophageal cancer and the incidence of OAC is lower than in the West (3). The current incidence of OSCC and OAC of several selected countries representing different geographic regions of Asia together with two Western countries, for comparison, is shown in table 1. Higher relative incidence rates of OAC are noted in major cities associated with higher living standards. Therefore, the national average of OAC incidence rates for India, Pakistan, the Philippines and China could be lower than those shown in table 1 . The incidence trends of $\mathrm{OAC}$ and $\mathrm{CC}$ in each country selected for the review are as follows;

Singapore, is a multiethnic country with rapid economic development and adaptation of western like lifestyle. A classic example of rising incidence of $\mathrm{OAC}$, similar to those observed in the West several decades back, is observed in Singapore. 


\begin{tabular}{|lcccrrr|}
\hline \multicolumn{1}{c}{ Country } & \multicolumn{2}{c}{ OSCC } & \multicolumn{2}{c}{ OAC } & \multicolumn{2}{c|}{ Relative OAC $^{\text {a }}$} \\
& Male Female & Male Female & Male Female \\
India (Chennai) & 6 & 7.8 & 0.4 & 0.1 & $6.7 \%$ & $1.3 \%$ \\
Pakistan (South Karachchi) & 5.3 & 7.5 & 1 & 0.3 & $18.9 \%$ & $4 \%$ \\
Philippines (Manila) & 14 & 0.3 & 0.6 & 0.1 & $4.3 \%$ & $33.3 \%$ \\
China (Shanghai) & 1.1 & 0.1 & 0.3 & 0 & $27.2 \%$ & $0 \%$ \\
China (Hong Kong) & 8.1 & 1.3 & 0.4 & 0.1 & $4.9 \%$ & $7.7 \%$ \\
Singapore & 3.9 & 0.8 & 0.6 & 0.2 & $15.4 \%$ & $25 \%$ \\
Korea & 6.5 & 0.3 & 0.3 & 0 & $4.6 \%$ & $0 \%$ \\
Japan (Osaka Prefecture) & 7.3 & 1.1 & 0.3 & 0 & $4.1 \%$ & $0 \%$ \\
Israel & 0.8 & 0.5 & 1 & 0.2 & $125 \%$ & $40 \%$ \\
Bahrain & 2.1 & 1.4 & 1.4 & - & $66.7 \%$ & - \\
USA (SEER data) & 1.9 & 0.8 & 3 & 0.4 & $157.9 \%$ & $50 \%$ \\
UK (East England) & 1.8 & 1.8 & 5 & 1 & $277.8 \%$ & $55.6 \%$ \\
& & & & & & \\
\hline
\end{tabular}

Table 1. Age-standardized incidence rates (W)/100,000 of OSCC and OAC and relative incidence of OAC (Source: cancer incidence in five continents volume $\mathrm{Ix}^{3}$ )

Fernandes et al have reported opposing incidence trend of OSCC and OAC in Singapore from 1968 to 2002 (23). Age standardized incidence rate (ASR) (per 100000 ) of OAC has risen from 0 to 0.54 for men and from 0 to 0.13 for women and the overall relative incidence of OAC has risen from $0.3 \%$ to $15 \%$ (Fig 1)(23). Deans et al have reported opposing incidence trend of CC and GNCC during 1968 - 2007, and the relative incidence of CC has risen from $6.7 \%$ to $19.3 \%$ (Fig 2 ).

Taiwan and South Korea, with higher socioeconomic standards in Asia, the relative incidence of OAC and CC has not changed significantly $(25,26,27)$. The actual incidence of CCandGNCChasalsonotchanged significantly in both countries $(25,26,27)$. In Taiwan, the relativeincidenceofOAChasbeen $3 \%$ to $4.1 \%$ and relative incidence of CC $25.2 \%$ to $22.5 \%$ during 1981-1995 (25). In South Korea, the relative incidence of OAC has been $3.8 \%$ to $2.9 \%$ during 1970-1999 and relative incidence of CC $6.6 \%$ to 7.4\%during1991-2000(26,27).

Japan, although the actual numbers of the OAC appeared to have increased, there are no marked changes in the relative incidence of OAC. The relative incidence of OAC in Japan, reported in several studies are as follows; $1.2 \%$ to $1.3 \%$ during $1973-1997 ; 3.5 \%$ to $4.3 \%$ during $1993-2001 ; 2.6 \%$ to $1.5 \%$ during $1980-94$ $(28,29,30)$. Kusano et al showed a rising incidence of adenocarcinoma involving the gastro-oesophageal junction from $2.3 \%$ to $10 \%$ during 1963 - 2005 (31). Opposing incidence trends of CC and GNCC have been a consistent finding in Japan, according to Blaser et al the relative incidence of $\mathrm{CC}$ has risen from $0.4 \%$ to $4.7 \%$ during 1969-97(30,32) (Fig 2).

China, a study carried out in Zhejiang Province, shows a rising incidence of both 


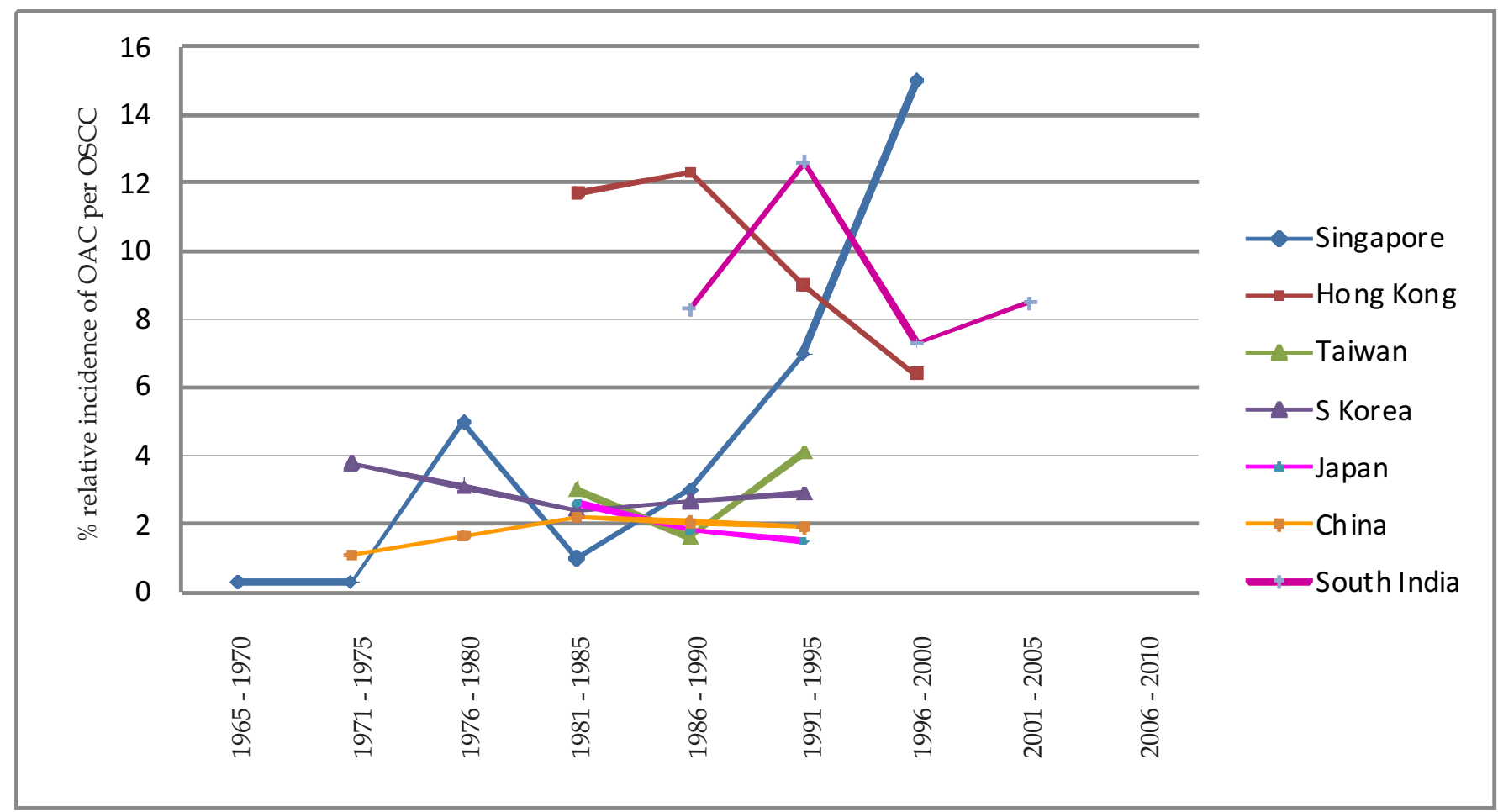

\section{Fig 1. Relative incidence trends of OAC}

OSCC and OAC, with stable relative incidence of OAC, viz,1.1\% to $1.9 \%$ from 1970 to 2001 (33). In Cixian county, where very high incidence of OSCC and CC are reported, ASR (per 100,000) of CC has increased significantly from 13.8 to 28.6 for males and from 7.1 to 12.9 for females during 1988-2003 (34). However, the incidence trends of the histological types of oesophageal carcinoma have not been addressed in this study. In Gansu province, increased incidence of proximal gastric carcinoma and declining incidence of gastric antral carcinoma has been reported during 1993-2004 (35). However, being a large country with significant geographical variations in living standards and life styles, China has varied incidences of OSCC, OAC and CC in different regions. Therefore, these studies carried out in different provinces are not comparable.

Hong Kong, is a region with high socioeconomic standards in Asia, and the relative incidence of $\mathrm{OAC}$ has been reported to be higher than in most other East Asian countries (36). However, in Hong Kong, ASR of both OSCC and OAC has decreased with a drop in relative incidence of OAC, from $10.5 \%$ to $6 \%$ during 1984-2003 (36) (Fig 1). Epidemiological studies on CC in Hong Kong could not be found in the literature.

India, published data depicting trends of OAC and CC are limited in South Asia. One Southern Indian population shows a higher incidence of OSCC with steady lower incidence of OAC; the relative incidence of OAC has been $8.3 \%$ to $8.5 \%$ during 1989-2004(37). However, another study in Southern India shows a progressive increase in incidence of OAC involving the gastrooesophageal junction during 1985-2004(38).

Sri Lanka, data from the National Cancer Control Programme (NCCP) shows that SCC is the most common type of oesophageal carcinoma. The incidence of OSCC has not shown a significant change in the trend. However, the incidence of OAC has progressively increased during 2000-2005 (Fig $3 a)$. The relative incidence of $\mathrm{OAC}$ has increased 


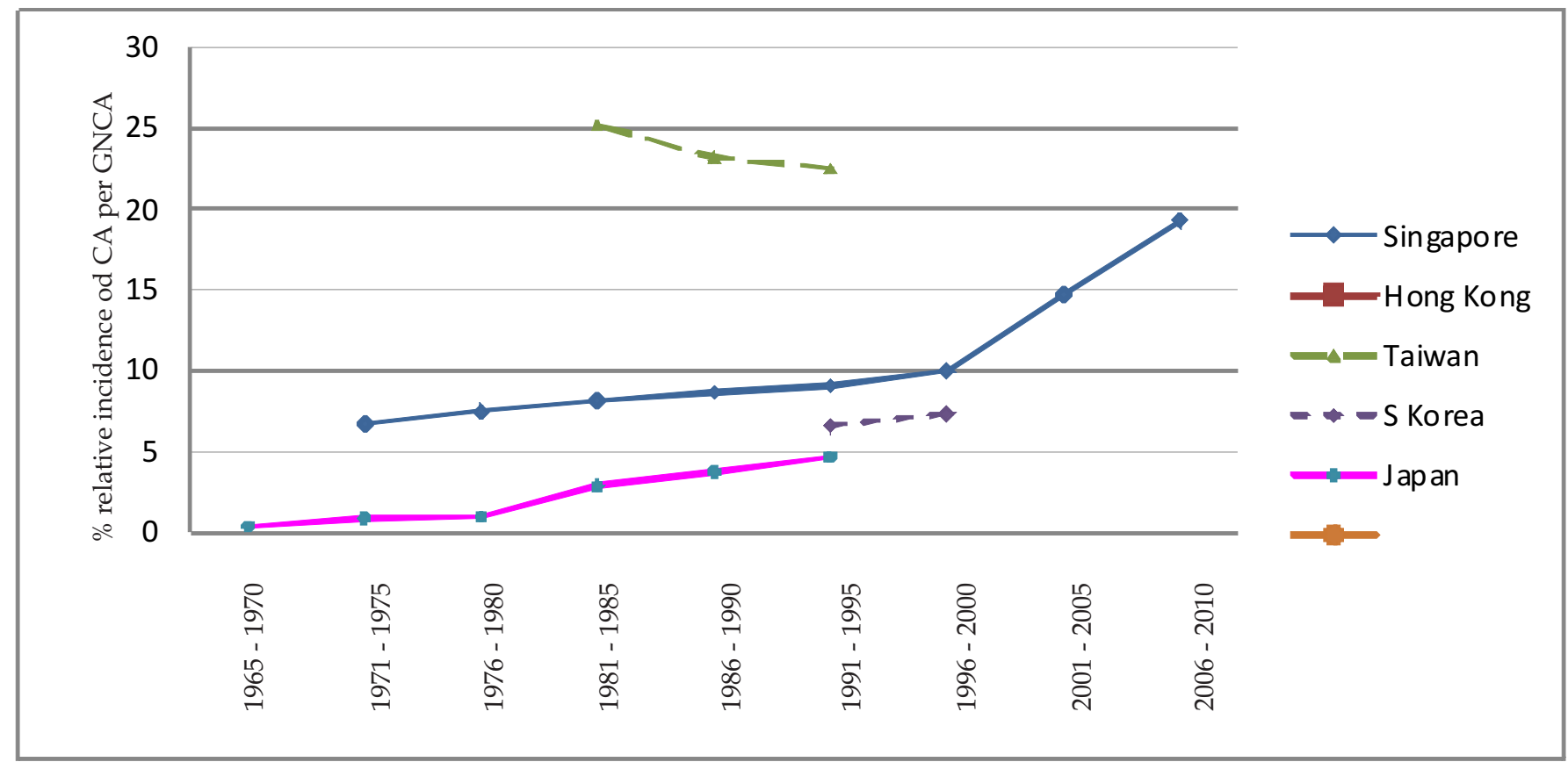

\section{Fig 2. Relative incidence trend of CC}

from $8 \%$ to $14 \%$ during this period (Fig $3 b$ ). The Incidence data of the histological types of oesophageal carcinoma are available in NCCP only from year 2000. The incidence of CC is unknown in Sri Lanka. However, there has been a drop in the ASR of oesophageal carcinoma and a small but progressive increase in the ASR of gastric carcinoma during 1995-2000 (Fig 4). of the gastric cancers, the site was not specified in NCCP data for 2005. Therefore, it is not possible to draw conclusions on the incidence of CC in Sri Lanka.

Asian oesophageal cancer belt, the Asian oesophageal cancer belt, which spans from the Caspian littoral of Iran across Afghanistan,

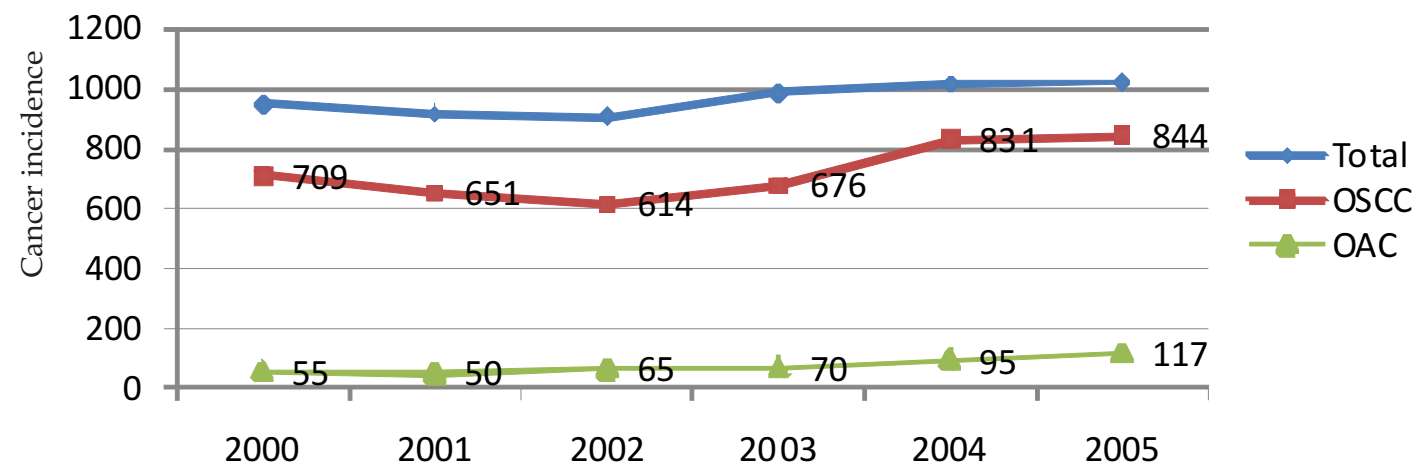

Fig 3a. Incidence of histological types of oesophageal carcinoma in Sri Lanka from 2000 to 2005

It is important to investigate whether or not this rise in gastric cancer incidence is due to increasing incidence of CC. However, in $88.8 \%$
Kazakhstan, Uzbekistan, Turkmenistan, and into northern China, has some of the highest incidence of OSCC in the world, and OAC 


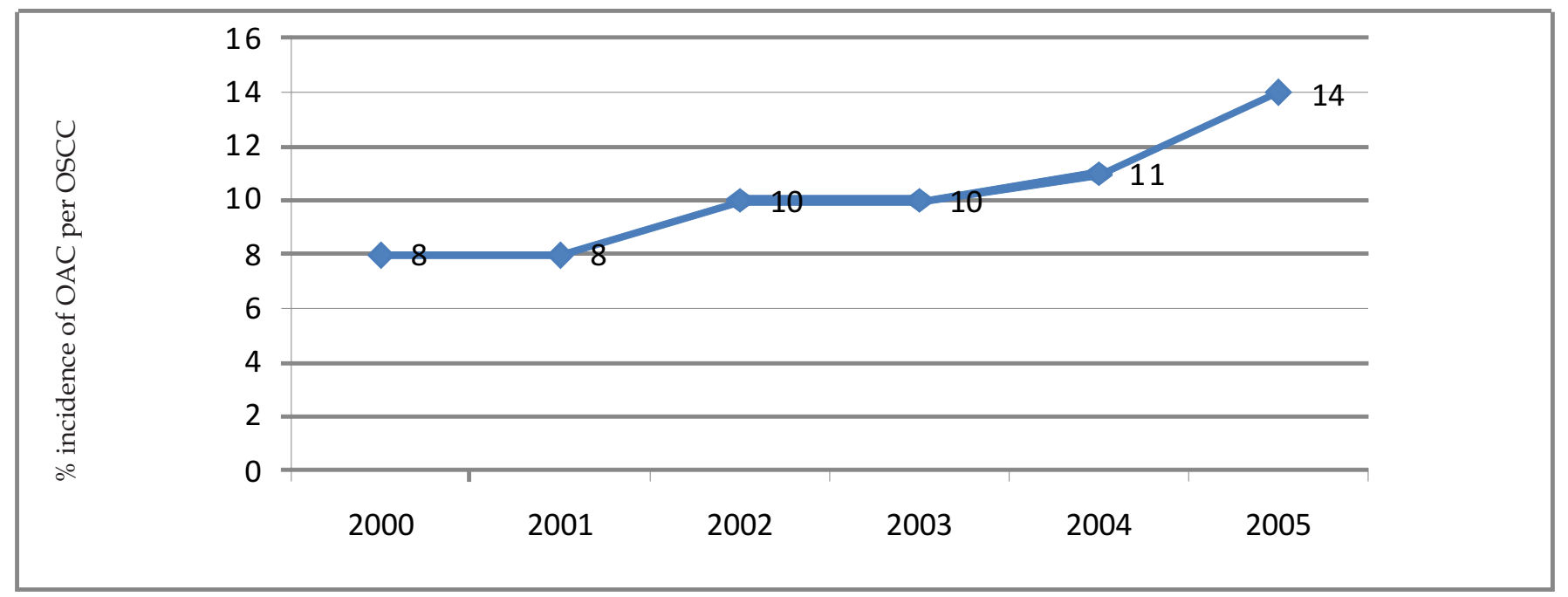

Fig 3b.Incidence of histological types of oesophageal carcinoma in Sri Lanka from 2000 to 2005. The trend of relative incidence of $O A C$

remains low in these regions (3,39). Published data regarding the incidence trends of OAC and CC are not available for these countries.

\section{Discussion}

In the reviewed East Asian countries trends of OAC have not been similar (Fig 1). The typical cultural features are more varied and complex in these countries than in the West. Despite improved socioeconomic status and adaptation of western like life styles, these East Asian countries have also maintained their local cultures and traditional life styles.This mixture of traditions and behavior, perhaps

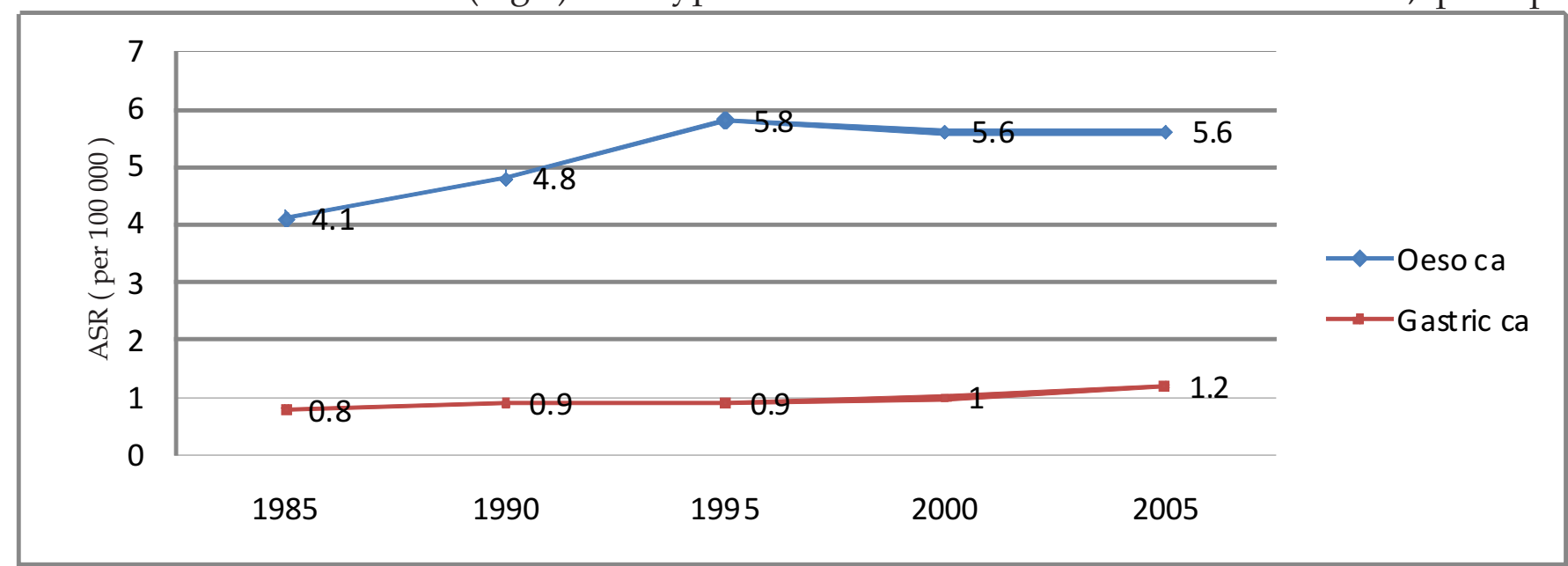

Fig 4. Age standardized incidence rates $(\mathrm{W}) / 100,000$ for oesophageal and gastric carcinoma in Sri Lanka from 1985 to 2005

rising pattern of $\mathrm{OAC}$ that was observed during the early part of the OAC epidemic in the West is seen only in Singapore. In Hong Kong, a declining trend of OAC is observed. Others have not shown marked differences in the incidence trends (Fig 1). Although the reasons for these observations are not readily apparent, it should be noted that socioeconomic and combined with different genetic profiles, may be responsible for observed differences in OAC trends. On the other hand, Singapore being a multi ethnic society appears to be more westernized than the rest of the East Asian countries. The socio economic standards and cultural features of South Asia are different from those of East Asia. Data from the South 
Indian population show steady incidence of OAC during the study period. The observed fluctuations in the relative incidence of OAC (Fig 1) are due to changes in the incidence of OSSC. Although there is a rising trend of OAC in Sri Lanka, the observed time period may be inadequate to draw conclusions. In all reviewed East Asian countries the relative incidence trends of CC appear to follow those of OAC regardless of the direction (Fig 2). However, it should be noted that the parameters used to measure the two trends are different. In most of these countries, CC and GNCC have shown opposing trends. Similar incidence trends of CC, OAC and GNCC have also been observed in North America and Western Europe $(4,14,15)$. These observations support the hypothesis that aetiopathogenesis of CC and GNCC are different.

There is controversy as to whether cardia carcinoma (CC) and junctional carcinoma are oesophageal or gastric in origin. Aetiologically, there are studies suggesting that, unlike in the distal stomach, intestinal metaplasia and adenocarcinoma in the cardia are not related to Helicobacter pylori infection $(18,19,20,21)$. Furthermore, several studies have produced evidence to suggest that adenocarcinoma arising in the lower oesophagus, gastro-oesophageal junction and cardia is one disease entity of oesophgeal origin and is aetiologically related to GORD $(9,10,18,21,22)$. Chandrasoma et al have proposed that the cardia, which is lined by nonspecialized columnar epithelium (cardiac mucosa), is the dilated distal part of the oesophagus due to GORD induced damage $(11,12,40,41)$. According to this hypothesis, The aetiopathogenesis of $\mathrm{CC}$ is similar to OAC and CC arises in the dilated distal oesophagus which anatomically appears as the proximal most part of the stomach $(11-13,21,22,40)$. Further supporting this hypothesis, the gene expression profile of intestinal metaplasia of the cardia has been shown to be similar to Barrett oesophagus and different to intestinal metaplasia of the distal stomach (42).

\section{Conclusion}

In the Asian countries SCC remains the most common oesophageal carcinoma. In the East Asian region, although incidence of OAC is relatively high, each country appears to have different incidence trends. In most East Asian countries, the relative incidence trends of CC appear to follow those of OAC, regardless of the direction of the trend and opposing trends are observed between CC and GNCC. These observations support the hypothesis that aetiopathogenesis of CC and GNCC are different. In South Asian countries, published data are not adequate to comment on the incidence trends of OAC and CC.

\section{Acknowledgement}

The authors acknowledge Dr. Neelamani Paranagama, Director, National Cancer Control Programme, Sri Lanka and Dr.K.G. Nirmala Jayanthi, National Cancer Control Programme, Sri Lanka,for the Support Provided in retrieving epidemiological data.

\section{References}

1. Cameron AJ. Epidemiology of columnar lined oesophagus and adenocarcinoma.Gastroenterology Clinics of NorthAmerica 1997; 26: 487 494.

2. Blot WJ, Devasa SS, Kneller RW, Fraumeni JF. Continued climb in rates of oesophageal adenocarcinoma:An update. The Journal of the American Medical Association 1993;270: 1320. 
Changing trend of oesophageal adenocarcinoma and cardia carcinoma incidence; review of literature and analysis

3. Cancer incidence in five continents volume IX. International Agency for Research on Cancer, WHO and International Association of Cancer Registries (http:/ / www.iarc.fr).

4. Devasa SS, Blot WJ, Fraumeni JF Jr. Changing patterns in the incidence of oesophageal and gastric carcinoma in the United States. Cancer 1998; 83: 20492053.

5. Yang CX, Wang HY, Wang ZM, Du HZ, Tao DM, Mu XY, et.al. Risk factors for esophageal cancer: a case-control study in South-western China. Asian Pacific journal of Cancer Prevention 2005; 6: 48-53.

6. Launoy G, Milan C, Day NE, Pienkowski MP, Gignoux M, Faivre J. Diet and squamous-cell cancer of the esophagus: a French multicentre casecontrol study. International Journal of Cancer 1998; 76: 7-12.

7. Melhado RE, Alderson D, Tucker O. The Changing Face of Esophageal Cancer. Cancers. 2010; 2: 1379-1404.

8. Haggitt $R$, Barrett's esophagus, dysplasia, and adenocarcinoma. Human Pathology. 1994; 25: 982-993.

9. Ruol A, Parent A, Zaninotto G, Merigliano S, Costantini $M$, Cagol $\mathrm{M}$, et al. Intestinal metaplasia is the probable common precursor of adenocarcinoma in Barrett esophagus and adenocarcinoma of the gastric cardia. Cancer 2000; 88: 2520-2528.

10. de Almeida JCM, Chaves P, Pereira AD, Altorki NK. Is Barrett's esophagus the precursor of most adenocarcinoma of the esophagus and cardia? A biochemical study. Annals of Surgery 1997; 226: 725-735.

11. Chandrasoma PT, Diagnostic atlas of Gastro-oesophageal Reflux disease. Academic Press 2007. New York, USA.

12. Chandrasoma $\mathrm{P}$, Wickramasinghe $\mathrm{K}$, Ma Y, DeMeester T. Is intestinal metaplasia a necessary precursor lesion for adenocarcinoma of the distal esophagus, gastro-oesophageal junction and gastric cardia? Diseases of the Esophagus 2007; 20:36-41.

13. Dent J, El-Serag HB, Wallander M-A, Johansson S. Epidemiology of gastrooesophageal reflux disease: a systematic review. Gut 2005; 54:710-717.

14. Blot WJ, Devasa SS, Kneller RW, Fraumeni JF. Rising incidence of adenocarcinoma of oesophagus and gastric cardia. The Journal of the American Medical Association 1991; 265: 1287-1289.

15. Corley DA, Buffler P. Oesphageal and gastric cardia adenocarcinoma: analysis of regional variation using the cancer incidence in five continents data base. International Journal of Epidemiology 2001;30: 1415-1425. 
16. Wijnhoven BPL, Siersema PD, Hop WCJ, van Dekken H. Adenocarcinoma of the distal oesophagus and gastric cardia are one clinical entity. British Journal of Surgery 1999; 86:529-535.

17. Leers JM, DeMeester SR, Chan N, et al. Clinical characteristics, biologic behavior, and survival after esophagectomy are similar for adenocarcinoma of the gastrooesophageal junction and the distal esophagus. Journal of Thoracic and Cardiovascular Surgery 2009; 138: 594-602.

18. Oberg S, Peters JH, DeMeester TR, Chandrasoma P, Hagen JA, Ireland AP, et al Inflammation and specialized intestinal metaplasia of cardia mucosa is a manifestation of gastrooesophageal reflux disease. Annals of Surgery 1997; 226:522-532.

19. Kamangar F, Dawsey SM, Blaser MJ, Perez-Perez GI, Pietinen P, Newschaffer CJ, et al Opposing risks of gastric cardia and noncardia gastric adenocarcinoma associated with Helicobacter pylori seropositivity. Journal of the National Cancer Institute 2006; 98:1445-1452.

20. Chow WH, Blaser MJ, Blot WJ, Gammon MD, Vaughan TL, Risch HA. An inverse relation between cagA+ strains of Helicobacter pylori infection and risk of esophageal and gastric cardia adenocarcinoma. Cancer Research 1998;58:588-590.
21. Wijetunge S, Ma Y, Hagen J, DeMeester $S$, DeMeester T, Chandrasoma PT. Association of adenocarcinoma of the oesophagus, "gastro-oesophageal junction" and "gastric cardia" with gastric pathology. American Journal of Surgical Pathology 2010;34: 1521-1527.

22. Chandrasoma P, Wickramasinghe K, Ma Y, DeMeester T. Adenocarcinoma of distal esophagus and "gastric cardia" are predominantly oesophageal carcinoma. American Journal of Surgical Pathology 2007; 31:569-575.

23. Fernandes ML, Seow A, Chan $\mathrm{YH}, \mathrm{Ho}$ $\mathrm{KY}$. Opposing trends in incidence of esophageal squamous cell carcinoma and adenocarcinoma in a multiethnic Asian country. American Journal of Gastroenterology 2006; 101: 1430-1436.

24. Deans C, Yeo MSW, Soe MY, Shabbir A, Ti TK, So JBY. Cancer of the Gastric Cardia is Rising in Incidence in an Asian Population and is Associated with Adverse Outcome World Journal of Surgery 2011;35: 617-624.

25. Chang SS, Lu CL, Chao JY, Chao Y, Yen SH, Wang SS, et.al. Unchanging Trend of Adenocarcinoma of the Esophagus and Gastric Cardia in Taiwan A 15Year Experience in a Single Center. Digestive Diseases and Sciences 2002; 47:735-740.

26. Son JI, Park HJ, Song KS, Kim KJ, Lee CY, Lee SI, et al A single center's 30 years' experience of esophageal adenocarcinoma. Korean Journal of 
Changing trend of oesophageal adenocarcinoma and cardia carcinoma incidence; review of literature and analysis

Internal Medicine 2001; 16: 250-253.

27. Lee JY, Kim HY, Kim KH, Jang HJ, Kim JB, Lee JH. No changing trends in incidence of gastric cardia cancer in Korea. Journal of Korean Medicine and Science 2000;318:53-57.

28. Hongo M. Review article: Barrett's oesophagus and carcinoma in Japan. Alimentary Pharmacology and Therapeutics 2004; 20: 50-54.

29. Shibata A, Matsuda T, Ajiki W, Sobue T. Trend in Incidence of Adenocarcinoma of the Esophagus in Japan, 1993-2001. Japanese Journal of Clinical Oncology 2008; 38: 464-468.

30. Blaser MJ, Saito D. Trends in reported adenocarcinoma of the oesophagus and gastric cardia in Japan. European Journal of Gastroenterology and Hepatology 2002; 14:107-113.

31. Kusano C, Gotoda T, Khor CJ, Katai $\mathrm{H}$, Kato H, Taniguchi H.Changing trends in the proportion of adenocarcinoma of the esophagogastric junctionina large tertiary referral center in Japan. Journal of Gastroenterology and Hepatology 2008; 23: 1662-1665.

32. Liu Y, Kaneko S, SobueT. Trends in reported incidences of gastric cancer by tumour location, from 1975 to 1989 in Japan. International Journal of Epidemiology 2004;33: 808-815.
33. Zhang $\mathrm{H}$, Chen SH, Li YM. Epidemiological investigation of esophageal carcinoma. World Journal of Gastroenterology 2004; 10: 1834-1835.

34. Hea TY, Houa J, Chena ZF, Qiaob CY, Songb GH, Mengb FS, et al. Trends in incidence of esophageal and gastric cardia cancer in high-risk areas in China. European Journal of Cancer Prevention 2008; 17:71-76.

35. Zhou Y, Zhang Z, Zhang Z, Wu J, Ren D, Yan $X$, et al. A rising trend of gastric cardia cancer in Gansu Province of China. Cancer Letters 2008; 269: 18-25.

36. Yee YK, Cheung TK, Chan AOO, Yuen MF, Wong BCY. Decreasing Trend of Esophageal Adenocarcinoma in Hong Kong. Cancer Epidemiology Biomarkers and Prevention 2007; 16: 2637-2640.

37. Cherian JV, Sivaraman R, Muththeusamy AK, Jayanthi V. Carcinoma of the esophagus in Tamil Nadu-16 year trends from a tertiary centre. Journal of gastrointestinal and liver disease 2007; 16: 245-249.

38. Tony J, Kumar SK, Thomas V. Time trends and pathological profile of carcinoma lower oesophagus and gastrooesophageal junction over the last 20 years-an experience from South India. Tropical Gastroenterology 2007; 28:113-116. 
39. Semnani S, Sadjadi A, Fahimi S, Nouraie M, Naeimi M, Kabir J,et.al. Declining incidence of esophageal cancer in the Turkmen Plain, eastern part of the Caspian Littoral of Iran: A retrospective cancer surveillance. Cancer Detection and Prevention 2006; 30:14-19.

40. Chandrasoma PT, Der R, Ma Y, Dalton $\mathrm{P}$, Taira M. Histology of the gastrooesophageal junction: an autopsy study. American Journal of Surgical Pathology 2000; 24: 402-409.

41. Chandrasoma P, Makarewicz K, Wickramasinghe K, Ma Y, Demeester T. A proposal for a new validated histological definition of the gastrooesophageal junction. Human Pathology 2006;37:40-47.

42. OhDS, Demeester SR, Tanaka K, Marjoram P, Kuramochi H, Vallbohmer $\mathrm{D}$, et.al. The gene expression profile of cardia intestinal metaplasia is similar to that of Barrett's esophagus, not gastric intestinal metaplasia. Diseases of Esophagus 2011(published ahead of print). 